\title{
Challenges and Motivational Facilitators of Social Accountability in Medical Students of Shiraz University of Medical Sciences: A Qualitative Study
}

\author{
Mahbobeh Mohammadi ${ }^{1}$, Mehdi Bagheri ${ }^{1}{ }^{,}$, Parivash Jafari (iD) ${ }^{2}$ and Leila Bazrafkan (iD ${ }^{3}$ \\ ${ }^{1}$ Bandar Abbas Branch, Islamic Azad University, Bandar Abbas, Iran \\ ${ }^{2}$ Science and Research Branch, Islamic Azad University, Tehran, Iran \\ ${ }^{3}$ Shiraz University of Medical Sciences, Shiraz, Iran \\ "Corresponding author: Bandar Abbas Branch, Islamic Azad University, Bandar Abbas, Iran. Email: mbagheri.sbu@gmail.com
}

Received 2019 September 28; Revised 2020 May 06; Accepted 2020 May 07.

\begin{abstract}
Background: Accountability in the community is one of the main missions of the medical school.

Objectives: The current study aimed at explaining the motivational facilitators and challenges in medical students of Shiraz University of Medical Sciences, Shiraz, Iran, for social accountability based on their experiences.

Methods: The current study using semi-structured interviews was conducted on 28 individuals, 16 of whom were students and 12 professors and managers of the medical school. Purposeful sampling was used up to saturation. Data were analyzed using the content analysis method. First, conceptual codes were extracted and then grouped into several main themes. Selected concepts or main themes included facilitators, inhibitors, or challengers.

Results: Selected concepts or main themes included facilitating factors and educational challenges for the social accountability of the students. The facilitators included informed choice, personality and moral commitment, content and process of motivation, promotion of community-based learning in the university, and the role of professors in motivation. The inhibitors or challenges included traditional routines, ineffective evaluations, manners of meeting the students' needs, the lack of educational facilities, and the impact of the increased number of students on the quality of education.

Conclusions: According to the current study findings, the conditions and facilities should be shared among medical education programs to provide a supportive environment for the students, and take a positive and effective step toward motivating them to improve their accountability.
\end{abstract}

Keywords: Social Accountability, Medical Student, Motivation, Challenge, Strategy

\section{Background}

One of the most challenging aspects of medical education is to learn how to motivate students in a long period of studying. Responsiveness in the community is one of the main missions of the medical school. In this regard, the World Health Organization, in its definition of social accountability, requires educational institutions to direct all the services, educations, and research activities to address the concerns and health priorities of the community $(1,2)$. Scholars consider social accountability a new paradigm for medical education and a kind of cultural change, and one of the four major missions of medical universities, which needs to be addressed in order to examine and comprehend the concept deeper (3). In all countries, one of the problems of the medical education system is the inabil- ity of medical graduates to respond to the growing needs of the community (4). Several studies on newly graduated physicians in the United Kingdom pointed to a lack of skills $(5,6)$. Heaton et al. (6), noted that many undergraduate medical students did not have sufficient knowledge and skills in the field of prescription, and they believed that the teaching and learning methods were not efficient enough. The social accountability problems of the general medicine curriculum are the lack of knowledge, attitudes, and skills of physicians corresponding to the needs of society. However, the lack of attention paid to social accountability in the training of physicians provides the ground for inducing inability in them to serve the community, thereby self-confidence is reduced, and anxiety is increased in the early years of practice (6-8).

Motivation in students depends on a variety of fac- 
tors, such as teaching methods practiced by faculty members and the learning environment $(9,10)$. In this regard, Kunanitthaworn et al. (9), studied the impact of various internal and external factors on motivating students to medicine, such as demographic characteristics, mental and psychological problems, positive personality traits, and perceived social support. They considered depression as an effective factor in motivation, which should be reduced to prevent academic failure and the lower quality of life in medical students (10). Gibbs and McLean, in another study beyond the national level, emphasized the need to design a global accountability model in international medical education systems. They believed that graduates of medicine should be prepared in their medical schools to respond to a variety of needs of the international community. They believed that this model should include responsibilities for all aspects of health care professional development in order to accommodate the global community than the setting in which medical education is provided (11). Ross et al. (12), using the term accountability, tried to review the first-year medical students' perception of physicians' accountability towards poor and deprived people. Using the qualitative content analysis, they analyzed the texts of 53 students and concluded that a limited number of them believed that there was no relationship between being physicians and having responsibility for underprivileged people (12).

Developed countries in the last 25 years developed and implemented outcome-based or competence-based curricula to enhance the ability of physicians on social accountability $(3,5)$. In Iran, several steps are taken in this regard, including the establishment of a healthcare network launched in 1981, integration of medical education and health services, and establishment of the Ministry of Health and Medical Education in 1984, which was a major step in social accountability of medical education $(5,13,14)$.

Although changes are made to educational programs and the learning strategy is revised $(3,11,15)$, the process of transferring theoretical knowledge to practical domains is not studied extensively, while considering philosophical and paradigmatic principles. Therefore, in the case of phenomena, when there is no or little knowledge of that phenomenon, the use of a qualitative approach based on the research questions verifies the method.

\section{Objectives}

The current study aimed at explaining the challenges and strategies to motivate social accountability in medical students of Shiraz University of Medical Sciences.

\section{Methods}

It was a qualitative content analysis study. Qualitative research provides an opportunity to focus on answering questions centered on social experimentation, how it is created, and how it makes sense to human life.

The belief that there are many facts that give meaning to the individuals' life constitutes the fundamental belief of the researchers of a qualitative research. One of the most important ways to identify the students' experiences is the motivation to respond to the use of the qualitative method (16-18). The research participants consisted of 16 different classes of students (basic sciences and clinical sciences) and 12 professors and managers of Shiraz University of Medical Sciences. They were selected using the purposeful sampling method. The interviews began with the proposal question and continued until the data saturation-i.e., the lack of receiving new information through theoretical sampling from 28 participants. The inclusion criteria for the students were at least five semesters studying at the faculty of medicine, and interest in participating in the research and expressing experiences. The interviews were conducted in a quiet place with participants in the library or hospital of Shiraz University of Medical Sciences. The interviews lasted 20 - 90 minutes.

Interviews were recorded using a voice recorder and transcribed immediately after the completion. The interview was held in a safe place, and the data of each were analyzed and codified immediately. In total, 1160 minutes of interviews were conducted, and the contents were carefully analyzed.

The main questions asked from the participants were "What experiences do you have in the medical school?, What motivates you? Did the orientation program motivate you? How?, and What are the obstacles and facilitators in the field for responsibility? During the interview, the participants were helped to concentrate. Follow-up questions were used if needed; for example, "Can you give an example? or Can you explain a little more about this?" Each interview ended with questions such as "Do you have a suggestion or a comment?, Do you think there is a question that has not been raised? and Do you want to ask me a question?"

Data were analyzed using content analysis. It helps to understand the discernible concepts of interpretations. For this purpose, first, by carefully reading the transcripts and describing the points for the participants, the researchers tried to understand the participants' feelings, and then important sentences and words were extracted from the transcripts. In the next step, the meanings were extracted, conceptualized, and coded. Initial codes that were related to each other and could form the potential 
themes were grouped into one. Then, each of the potential themes was reviewed and adapted to the participants' statements, and the final themes were determined (19).

\subsection{Rigor}

In order to explain the accuracy and rigor of data, which is one of the features of qualitative research, four criteria of Lincoln and Goba (i.e., credibility, transferability, dependability, and confirmability) were applied $(18,20)$.

Credibility and conformability of the data were confirmed by the allocation of adequate time to interviews for a real understanding of the data and establishing appropriate communication. The researchers tried to avoid any prejudice against the phenomenon studied before and after the interview. Reviewing the extracted codes and themes was performed by two research assistants accepting the codes and categorization of themes, and the controversial issues were discussed to reach a final agreement. Review by the observers included the application of complementary comments of the colleagues (peer review) and the confirmation of the level-one codes by a number of collaborators (member check). Searching for contradictory data and analyzing negative data were performed through the transcripts and among them.

\subsection{Ethical Considerations}

The current study was approved by the Ethics Committee of Islamic Azad University, Hormozgan Branch (code no.: 5965). At the beginning of the interview, the study objectives, the employed method, the way of conducting the interview, and the freedom to withdraw from the study were explained to the participants. Confidentiality of the information was observed, and informed consent for interviewing and its recording were obtained. The right to withdraw from the study at any time was one of the observed ethical considerations.

\section{Results}

A total of 28 individuals were interviewed from different medical grades. All concepts were related to each other and provided a pattern of teaching experience to respond and motivate students in both basic and clinical sciences, and help the reader understand the reality of the motivation of medical students to respond. The results are shown in Table 1.

\subsection{Factors Facilitating Motivation for Accountability}

Based on the participants' experiences, accountability is referred to as the amount of the student's attention paid to attain knowledge, attitude, and competence for the future needs of the patients and society; this is acquired when the student has enough motivation to achieve proficiency in medicine. Therefore, if the colleges want to meet the community requirements through education, students should be chosen based on specific criteria so that they can remain accountable in the future. One of the participants said: "Interest in medical profession helps the students to get involved in the acquisition of competence. My experience shows that the sufficiently of students interested in medicine is more accountable and active." (faculty member no.: 15).

In this issue, few subthemes, including informed choice, personality and moral commitment, content and process of motivation, promotion of community-based learning in the university, and the role of professors in motivation, emerged.

\subsection{Informed Choice}

The informed choice was the main effective intervention in the motivation of medical students for social accountability. The choice of the field of study is important since determining the fate of individuals is influenced by a variety of factors divided into external and internal categories. These factors that are partly beyond the control, directly and indirectly, affect his choice. One of the participants said: "I selected medicine as my aunt was a physician, and I knew the problems and hardships of becoming a doctor. I also knew that physicians have a lot of responsibilities" (student no.: 4).

In some cases, this effect occurs in the long term, and some others in the short run and immediately. Understanding these factors can help us make a better choice. External factors include the family, educational environment, individuals influencing the lives of others, peer groups, mass media, the advancement of science and technology, economic, cultural, and social context, and the acceptance of the labor market. The internal factors affecting the choice of the field of study include intelligence and talent, interest and willingness, values and attitudes, beliefs, gender, abilities, and skills. One of the participants said: "I think the major choice is based on personal knowledge and desire. If students are given the chance to choose freely, the result would be their responsibility and accountability in their medical profession and society" (student no.: 6).

Based on the experiences of the participants, interest is personal and intrinsic, and they thought that they had a particular talent in medicine and community services; in other words, it was their personal and intrinsic interest, which guided the medical students and boosted their selfesteem. In this regard, a successful student said: 


\begin{tabular}{|c|c|c|}
\hline Theme & Subtheme & Thematic Unit \\
\hline \multirow{5}{*}{$\begin{array}{l}\text { Factors facilitating motivation for } \\
\text { accountability }\end{array}$} & Informed choice & $\begin{array}{l}\text { If the student is aware of the future gains and difficulties of } \\
\text { his chosen major, he prepares himself to be accountable. }\end{array}$ \\
\hline & Personality and moral commitment & $\begin{array}{l}\text { Anybody has specific talents, principles, beliefs, and values } \\
\text { formed before } 18 \text { years of age, and now they are only } \\
\text { directed and oriented. }\end{array}$ \\
\hline & Content and process of motivation & $\begin{array}{l}\text { The medical profession has attraction and respect, and this } \\
\text { persuades students toward it. }\end{array}$ \\
\hline & Promotion of community-based learning in the university & $\begin{array}{l}\text { The prevalence of accountability and community-based } \\
\text { learning in the university contributes to the accountability } \\
\text { of the faculty member to the students, and prepare him for } \\
\text { future accountability. }\end{array}$ \\
\hline & The role of professors in motivation & $\begin{array}{l}\text { On clinical rounds, my teacher is a role model for me, so he } \\
\text { encourages me to be accountable in my career. }\end{array}$ \\
\hline \multirow{3}{*}{$\begin{array}{l}\text { Challenges to motivate students to } \\
\text { be accountable }\end{array}$} & Traditional routines & $\begin{array}{l}\text { Some people do not agree with any change, and stick to } \\
\text { their traditional approaches. The world has changed; why } \\
\text { don't you want to change in the 21st century. }\end{array}$ \\
\hline & Ineffective evaluations How to meet students' needs & $\begin{array}{l}\text { I could not perform a lumbar puncture and this bothered } \\
\text { the patient. However, nobody told me why I could not and } \\
\text { what I had to do to solve the problem. }\end{array}$ \\
\hline & Lack of educational facilities & $\begin{array}{l}\text { When we do not have enough consumables, such as glass } \\
\text { for drinking water, the condition for hospital equipment is } \\
\text { worse. Why do you admit so many students? How can you } \\
\text { educate and train them? }\end{array}$ \\
\hline
\end{tabular}

"I think success and ultimately meeting the community needs are highly relevant to IQ, which is intrinsic. The one who is smarter can enter the medical school, and I think it is enough for self-confidence, development, and accepting responsibility in the future" (student no.: 7).

\subsection{Personality and Moral Commitment}

According to the participants' statements, student's personality and moral commitment were the main indicators of becoming accountable, since moral commitment is among the main factors in how to act and create a suitable platform to motivate development, use the existing facilities, and understand the community problems. This factor helps the students feel responsible and commit their duties during studying, and respect the ethical principles and laws governing their profession and field of study. It also refers to the characteristics of professional ethics, such as the sense of responsibility, conscientiousness, honesty, respect for others, respect for social values and norms, justice, and fairness. One of the professors said:

"I find many of the traits in my teachers in the university, including being disciplined, having good information and being up-to-date, spending time for students, and good management, which are the results of their high moral commitment." (faculty member no.: 17).

The experiences of the participants showed that the ethical obligations of the medical profession are derived from their personality, and these traits are formed before choosing this specialty. Nevertheless, courses and educational programs can be effective in guiding and improving the behavior of the students. One of the professors stated: "It is a fact that personality is formed within the family, but to a large extent, our programs can guide the students to be responsible and accountable in their medical profession and that how it differs from other professions" (faculty member no.: 16).

\subsection{Content and Process of Motivation}

The realism of medical work and its content-based theoretical and practical education and content motivation in terms of the attractiveness of medical topics and processes are among the factors attracting students. Based on the experiences of the participants, medical education itself is attractive for everyone. The content of courses and educational topics also increases the interest in this field [Ma1]. This attraction moves the students to gain sciences along with action and accountability.

One student said: "Medical work is, in fact, a specialty that requires a deep love, and not anyone can do it. Another issue is that the medical content itself is attractive enough and motivates learning" (student no.: 6).

Regarding the motivation process, the participants also believed that the medical field is unique due to the importance of human life and historical record; therefore, people are respectful to this subject and its practitioners.

One of the professors said: 
"The community currently does not know a series of facts about medicine, but the respect that people have for this discipline and doctors and its credibility is still significant" (faculty member no.: 15).

\subsection{Promotion of Community-Based Learning in the University}

According to the participants, the promotion of community-based learning at the university in recent years motivated students to take on future responsibilities and pay attention to their current practical, theoretical, and clinical teaching status. Community-based education responds to the needs and expectations of the community. In this respect, one of the faculty members said:

"The responsive education facilitates the process of accountability and motivation in the students. In case the student notices that the faculty members and managers are working on this issue and hold seminars, he can consider what this accountability is" (faculty member no.: 19).

In other words, community-based education means being accountable. From its perspective, any decision made at each level of the educational system should facilitate responding to the needs and expectations of the community. If responding to the needs and expectations of the society and dynamic interaction between education and society is a rational, continuous, and sustained demand, community-based education should also indicate a permanent and sustainable movement towards meeting the needs of the society. Therefore, community-based education does not present a still image of an ideal condition, which responds to all the needs and expectations of the community, but rather a moving image toward perfection. In this regard, one of the professors said:

"Since the society and accountability are the strategies that we must always strive to achieve, and it is important to create a community-based perspective in the student in order to prepare them meet the needs of the people in the future" (faculty member no.: 14).

\subsection{The role of Professors in Motivation}

The performance of professors in both basic and clinical sciences affects the motivation of students and, consequently, their accountability in the future from two aspects-i.e., the professor can transfer his experiences to students via the integration of knowledge, behavior, and word and, on the contrary, reducing their motivation. The characteristics of professors were: being interested and experienced, having a good scientific knowledge, the skills of making communication with the department, the ability to establish an effective communication with students, high clinical performance, respect for students and repeating the content with patience, high self-confidence, accountability, identifying and reinforcing students' strengths, and supporting them for motivation and learning.

One of the students said:

"When Dr. ... comes to class and speaks, you feel he is giving all his heart to teach and educate the students to feel accountable. He wishes to transfer everything he knows. When the teacher is experienced, we learn more from him because he feels responsible for medicine, and this sense of responsibility has led him to work with all the power, and he is glad to welcome this class. Then the learners conclude that they are also responsible and responsive to patients" (student no.: 12).

\subsection{Challenges to Motivate the Students to be Accountable}

Based on the experiences of the majority of participants, the professor can act as the facilitator and model for learning. However, some participants believed that lack of experience, mastery, confidence, and aggression of instructor are the factors that disrupt students' mental order and motivation to participate in class, thereby causing a lack of accountability and responsibility in the future.

One of the students argued in this regard:

"When the professor is rude and selfish, does not respect the student, is so proud of himself, wants everyone to accept everything he says, and only speaks and does not consider the circumstances of the other side, how do I learn responsibility and accountability from him? If I have questions and talk to him, he does not pay attention" (student no.: 3).

Based on the experiences of students, under such circumstances, students should not be expected to have a different attitude and behavior, focus on teaching and learning, and ultimately become accountable to society and patients. These challenges include traditional routines, ineffective evaluations, ways to meet the students' needs, lack of educational facilities, and the impact of the increased number of students on the quality of education.

\subsection{Traditional Routines}

Based on the experiences of participants, traditional routines are challenges to motivate the students for accountability. The lack of interpersonal communication skills at the time of entering the university, the bulk of the courses, and excessive reliance on learning by memory are part of the routine education. Unfortunately, this undermines the efforts of a number of professors and practitioners-i.e., the lack of application of the modern approaches to these circumstances, transfer of knowledge, and using it in practice. In this regard, one of the managers said: "Faculty members are accustomed to their traditional 
approaches and do not agree with any new idea. Some believe that their methods are appropriate and there is no need for changes" (faculty member no.: 28).

What we mean by the traditional approach is that general programs are institutionalized around the professors to the extent that even after useful alterations to the program, it still takes on a traditional approach.

As to the impact of curriculum integration, one of the students said:

"An important problem for us is to establish links between different lessons or integrate them for use. However, the integration can be very good, but not enough, and we do not feel that the subject is integrated but merely mixed, and it disturbs our thoughts" (student no.: 19).

\subsection{Ineffective Evaluations}

Ineffective evaluation is the title taken from the participants' statements and experiences in evaluation problems. According to participants, evaluation of problems is categorized as student evaluation and professor evaluation. It has some effects on the motivation of students and professor's effort to empower himself to respond to the students, university, and society. Teacher evaluation is possible by collecting the necessary data about the teacher's educational activities and comparing the information obtained based on standard or predetermined criteria. But how this assessment is implemented is very important, which has a valid and consistent result for the interpretation and follow-up of students in this field.

One of the students said:

"It is important how to perform the evaluation. We rush to fill out a questionnaire that does not properly ask how the professor was, and the outcome is not credible ... The evaluation of students also has its problems. Sometimes we find that there is not much connection between the lessons and the exam. For example, clinical skills are assessed by written and multiple-choice tests" (student no.: 8).

Evaluation is an important factor in the advancement of educational goals. However, the participants' experiences indicated that the low validity and reliability of the instruments and methods used to evaluate students or professors cause challenges and complexities.

\subsection{How to Meet the Students' Needs}

How to respond to the students' needs was one of the most important themes extracted from the participants' experiences. This class is made up of two subclasses of non-compliance with curriculum requirements for the students. It appears during inadequate accountability and reflects the underlying challenges in the process of motivating for social accountability. The phenomenon of responding to the needs of the students is a common ground among professors, students, and managers. Professors and students found it difficult to adhere certain lessons and programs; in addition, not considering the necessary programs and the lack of students' knowledge and skills in this area make the situation hard for the students and professors, and they are confused due to the ambiguity in the curriculum and their roles. Ineffective evaluation of the professors adds to the problem and leads to the reaction of professors and students-e.g., indifference. In this way, the professor feels accountable in a complicated process and cannot succeed in programs developed based on the needs of the community and education, or is not successful, resulting in student dissatisfaction and the presence of unintended and non-responsible graduates. Students at this stage experience uncertainty and confusion. The compulsory curriculum, as well as the preferences of professors and students, puts them in an uncertain position. One student said:

"I do not know why there are so many different programs in the university that do not affect our abilities. There are a lot of lessons that take a lot of energy".

Professors also said that they are skeptical about the need to teach some lessons (student no.: 16).

\subsection{Lack of Educational Facilities}

The other side of support refers to the facilities and use of available equipment. Inadequacy and even lack of resources in all fields, including financial resources, study resources, and laboratory, were emphasized by the participants. They considered these shortages as the cause of many disasters and problems. One of the students argued the impacts of shortages:

"I wanted to get enough training in some skills before entering the hospital, but I couldn't" (student no.: 10).

The participants' experiences highlighted the importance of scientific knowledge and communication at university. As a general rule, they considered the most successful person as the one who has the best and most accurate information and is in contact with the experts in his field. If scientific resources and libraries do not meet the needs of the professors and students, due to particular circumstances, the consequences of this shortage affect the academic life of the university and the professors. One of the students said: "When we claim we are accountable-e.g., to the elderly, but there are no sufficient facilities to take proper measures, the student thinks that accountability is nothing but a motto" (student no.: 9). 
4.12. The Impact of the Increased Number of Students on the Quality of Education

The drop in the students' quality of education at different levels was the other concern of the three participating groups in the study. Professors and managers pointed out that, unfortunately, our educational system does not pay much attention to the thinking and analysis, and emphasizes the ability of memorization more than anything else. As a result, most students are incapable of critical skills, such as writing, analyzing, engaging in complex tasks, as well as linguistic abilities. One of the professors said:

“If we look at the students' status deeply, their knowledge and abilities at all levels (student, resident, $\mathrm{PhD}$ ) have relatively decreased (I have dealt with students of all these levels). It seems that some are only here to get their degrees" (faculty member no.: 25).

\section{Discussion}

The current study findings showed that facilitators of motivation for social accountability in medical students are the conscious choice, content and process of motivation, and promotion of community-based education. Conscious choice means choosing a medical discipline while being aware of its requirements, along with personal competencies. If the circumstances, based on personal competencies, are provided for this conscious and targeted choice, then the students can be motivated for accountability. Patterson et al. (21), examined the importance of making conscious choices of the field of study and right choice of students in a systematic review study. The results revealed that educational records and results of multiple mini interviews and ability tests were the more practical selection methods, and generally, relative to traditional interviews, personal remarks are better standards of competence (21).

The participants in the present study defined the content and process of motivation as the attractiveness of educational content, and the reputation of the study field as the main reason for attracting the most talented applicants. There are many studies on the reasons for choosing a medical discipline; in most of them, social dignity and high income are attractive to people who select this discipline. The study by Rooshan Taj and Zourofi (22), also showed a significant and positive correlation between looking for a degree and a high-income job in the selection of a field of study, as well as between other encouragements and cultural capitals, and personal interest, social prestige, income, and labor market. In this regard, Shakornia et al. (23), concluded that the factors affecting the choice of this study field are benefitting from community services, high income, and social position; in addition, with the increase of years of study at university, motivity and interest of the students in medical studies reduce.

The study by Ibrahim et al. (24), in the United Kingdom showed that social credibility and role-playing in the community are regarded as attractions of medical sciences as the study field, which can be an incentive for accountability. The promotion of a community-based perspective in university is among the facilitators of accountability in the students. Several studies in Iran also indicated that the medical sciences universities in recent years made critical contributions to community education (24-26). For example, integration at Shiraz University of Medical Sciences carried out on horizontal and vertical levels had satisfactory results (15).

The findings of the current study showed that the performance of professors could act as a facilitator in the process of education and, as a result, create accountability in students. It seems that the implementation of the learning-teaching process by efficient and effective instructors can empower the students to better benefit from their abilities. Clinical professors can tremendously improve the quality of clinical education and make clinical experiences enjoyable for the students; also, competent students can respond more effectively than the incompetent ones (27).

The traditional routines, inadequate evaluation, and lack of environmental facilities are among the challenges of the process of motivating students for social accountability; each intervenes in engagement and motivation, causing anxiety and inability to respond to the needs of society in the future.

The traditional routine does not mean receiving a change in education and turning programs to the time before. Based on the experiences of the participants, traditional routines threaten the work of the modern academics and innovative programs, and in some cases, completely neutralize them.

Studies show that it is essential for professors to modify their educational approaches to institutionalize accountable learning, which can influence their role as a traditional lecturer. The mission of medical universities and faculty members is to empower the graduates to accept important occupational roles (28). Universities, with the participation of academics, deliver students to the community, who, in addition to having the necessary knowledge and skills to perform community services, meet the expectations of the national and local community, and have the capabilities to accelerate developments of the 21st century (29). Today the health system requires graduates with higher capabilities in problem-solving, critical thinking, technology and information resources, communication skills, comprehensive and community-based attitudes to- 
ward health, conducting evidence-based practice and clinical reasoning, and respecting the professional ethics. The student-centered is a strategy in this regard, and the lecturer should shift from the traditional lecture to smallgroup, problem-based, and research-based learning (30). The findings also revealed ineffective evaluation in this process; that is, the students do not receive any feedback on their knowledge and ability, and the professors do not get constructive feedback on their behavior towards students. Studies show the positive effect of using effective evaluation on the students' theoretical and clinical aspects of learning (30-32).

It is also expected to use modern assessment methods, such as logbook, portfolio, and objective structured clinical examination. Professors should provide the students with a variety of learning experiences and measure the students' capabilities properly (32).

Lack of equipment and environmental facilities leads to the lack of adequate training opportunities for preclinical skills in order to ensure sufficient capacity for entry into the internship period. Findings showed that one of the subthemes of challenges was lack of equipment and environmental facilities. Other studies reported problems with the clinical setting. They showed that students are not satisfied with their facilities and equipment, and they emphasize the provision of more and high-quality resources $(33,34)$. It is suggested that more prominence should be placed on the students' experiences and opinions about the quality of educational services in universities, to generate a reasonable atmosphere in universities and affect the more interested students to be socially responsible.

\subsection{Application of Results}

The current study findings can be useful to improve student admission policies. Students should choose the field of medicine consciously and according to their interests. These results can be applied in university and medical curriculum planning to pinpoint what programs should exactly be designed to meet the requirements of responsible and accountable students. Administrators and staff should be informed that shortcomings not only affect the quality of education, but they also affect how learners respond in the future.

\subsection{Conclusions}

Therefore, motivation in medical students to be accountable to community needs is the result of interaction between different variables, such as professors, students, and curriculum. However, there are also facilitators and challenges; in other words, students feel accountable when they have an acceptable level of motivation at the time of entering university, if they witness responsible behavior and accountability in all components of the educational process, including curriculum and professors. In this context, the convergence among the teacher, students, and the student accountability process should be facilitated.

\section{Footnotes}

Authors' Contribution: Study concept and design: Mahbobeh Mohammadi. Analysis and interpretation of data: Mahbobeh Mohammadi and Leila Bazrafkan. Drafting of the manuscript: Mahbobeh Mohammadi. Critical revision of the manuscript for important intellectual content: Mahbobeh Mohammadi and Mehdi Bagheri. Statistical analysis: Mahbobeh Mohammadi and Parivash Jafari.

Conflict of Interests: The authors declared no conflict of interest.

Ethical Approval: Ethical approval was not applicable to the present study.

Funding/Support: No funding was provided for this article.

Informed Consent: Confidentiality of the information was observed, and informed consent for interviewing and recording of the conversations was obtained.

\section{References}

1. Entezari A, Momtazmanesh N, Khojasteh A, EYN EB. Toward social accountability of medical education in Iran. Iran J Public Health. 2009;38(Suppl 1):27-8.

2. Woollard RF. Caring for a common future: medical schools' social accountability. Med Educ. 2006;40(4):301-13. doi: 10.1111/j.1365 2929.2006.02416.x. [PubMed: 16573665].

3. Boelen C, Heck JE; World Health Organization. Defining and measuring the social accountability of medical schools. Geneva: World Health Organization; 1995.

4. Karimi S, Zohoorparvandeh V. Need assessment of the general practitioner's curriculum based on clinical activities, advocacy, research, and education (CARE) model. Future of Medl Educ J. 2019;9(1):18-24.

5. Emadzadeh A, Karimi Moonaghi H, Bazzaz MM, Karimi S. An investigation on social accountability of general medicine curriculum. Electron Physician. 2016;8(7):2663-9. doi:10.19082/2663. [PubMed: 27648195]. [PubMed Central: PMC5014507].

6. Heaton A, Webb DJ, Maxwell SR. Undergraduate preparation for prescribing: The views of 2413 UK medical students and recent graduates. $\mathrm{Br} J$ Clin Pharmacol. 2008;66(1):128-34. doi: 10.1111/j.1365-2125.2008.03197.x. [PubMed: 18492128]. [PubMed Central: PMC2485268].

7. Brinkman DJ, Tichelaar J, Schutte T, Benemei S, Bottiger Y, Chamontin $\mathrm{B}$, et al. Essential competencies in prescribing: A first european crosssectional study among 895 final-year medical students. Clin Pharmacol Ther. 2017;101(2):281-9. doi: 10.1002/cpt.521. [PubMed: 27648725]. [PubMed Central: PMC5260337].

8. Strasser RP, Lanphear JH, McCready WG, Topps MH, Hunt DD, Matte MC. Canada's new medical school: The Northern Ontario School of Medicine: Social accountability through distributed 
community engaged learning. Acad Med. 2009;84(10):1459-64. doi: 10.1097/ACM.0b013e3181b6c5d7. [PubMed: 19881443].

9. Kunanitthaworn N, Wongpakaran T, Wongpakaran N, Paiboonsithiwong S, Songtrijuck N, Kuntawong P, et al. Factors associated with motivation in medical education: A path analysis. BMC Med Educ. 2018;18(1):140. doi: 10.1186/s12909-018-1256-5. [PubMed: 29914462]. [PubMed Central: PMC6006981].

10. Boelen C. Coordinating medical education and health care systems: The power of the social accountability approach. Med Educ. 2018;52(1):96-102. doi: 10.1111/medu.13394. [PubMed: 28884465].

11. Gibbs T, McLean M. Creating equal opportunities: The social accountability of medical education. Med Teach. 2011;33(8):620-5. doi: 10.3109/0142159X.2011.558537. [PubMed: 21774647].

12. Ross PT, Williams BC, Doran KM, Lypson ML. First-year medical students' perceptions of physicians' responsibilities toward the underserved: An analysis of reflective essays. J Natl Med Assoc. 2010;102(9):761-5. doi: 10.1016/s0027-9684(15)30672-6. [PubMed: 20922919].

13. Ahmady S, Akbari Lakeh M. Exploring the practical themes for medical education social accountability in Iran. Gastroenterol Hepatol Bed Bench. 2015;8(1):28-32. [PubMed: 25584173]. [PubMed Central: PMC4285929].

14. Rajabi F, Majdzadeh R, Ziaee SA. Trends in medical education, an example from a developing country. Arch Iran Med. 2011;14(2):132-8. [PubMed: 21361721].

15. Rooholamini A, Amini M, Bazrafkan L, Dehghani MR, Esmaeilzadeh $Z$, Nabeiei P, et al. Program evaluation of an Integrated Basic Science Medical Curriculum in Shiraz Medical School, Using CIPP Evaluation Model.J Adv Med Educ Prof. 2017;5(3):148-54. [PubMed: 28761888]. [PubMed Central: PMC5522906].

16. Rahimi H, Kalantari A, Rafiee N, Khosravi S. Social trends affecting the future of iran's health system: A qualitative study using focus group discussion.IntJPrev Med.2019;10:115.doi:10.4103/ijpvm.IJPVM_322_18. [PubMed: 31367279]. [PubMed Central: PMC6639845].

17. Flick U. An introduction to qualitative research. California: Sage Publications Limited; 2018.

18. Tracy SJ. Qualitative research methods: Collecting evidence, crafting analysis, communicating impact. USA: John Wiley \& Sons; 2019.

19. Assarroudi A, Heshmati Nabavi F, Armat MR, Ebadi A, Vaismoradi M. Directed qualitative content analysis: The description and elaboration of its underpinning methods and data analysis process. $J$ Res Nurs. 2018;23(1):42-55. doi:10.1177/1744987117741667.

20. Korstjens I, Moser A. Series: Practical guidance to qualitative research. Part 4: Trustworthiness and publishing. Eur J Gen Pract. 2018;24(1):120-4. doi: 10.1080/13814788.2017.1375092. [PubMed: 29202616].

21. Patterson F, Knight A, Dowell J, Nicholson S, Cousans F, Cleland J. How effective are selection methods in medical education? A systematic review. Med Educ. 2016;50(1):36-60. doi: 10.1111/medu.12817. [PubMed: 26695465].
22. Rooshan Taj N, Zourofi M. The relationship between social and cultural factors with the selection of field of study criteria among Islamic Azad University students. J Soci Stud. 2015;7(81-97).

23. Shakornia A, Khajeh Ali N, Bagheri A, Bijanzadeh M. Factors affecting medical major selection and the extent of changes in students' motivation during their study in Ahvaz Jundishapur University of Medical Sciences. Iran J Med Educ. 2016;16:189-99.

24. Ibrahim M, Fanshawe A, Patel V, Goswami K, Chilvers G, Ting M, et al. What factors influence British medical students' career intentions? Med Teach. 2014;36(12):1064-72. doi: 10.3109/0142159X.2014.923560. [PubMed: 24934092].

25. Nejati M, Ghasemi S. Corporate social responsibility in Iran from the perspective of employees. Soc Responsib J. 2012;8(4):578-88. doi: $10.1108 / 17471111211272552$.

26. Mahmoudi G, Jahani MA, Hoseini Rostami F, Mahmoudjanloo S, Nikbakht H. Comparing the levels of hospital's social accountability: Based on ownership. Int J Healthcare Manage. 2017;11(4):319-24. doi: 10.1080/20479700.2017.1417074.

27. Faulkner LR, McCurdy RL. Teaching medical students social responsibility: The right thing to do. Acad Med. 2000;75(4):346-50. doi: 10.1097/00001888-200004000-00010. [PubMed: 10893116].

28. Mokadam NA, Dardas TF, Hermsen JL, Pal JD, Mulligan MS, Jacobs LM, et al. Flipping the classroom: Case-based learning, accountability, assessment, and feedback leads to a favorable change in culture. JThorac Cardiovasc Surg. 2017;153(4):987-996 e1. doi: 10.1016/j.jtcvs.2016.10.101. [PubMed: 28088430].

29. Ramnanan CJ, Pound LD. Advances in medical education and practice: Student perceptions of the flipped classroom. Adv Med Educ Pract. 2017;8:63-73. doi: 10.2147|AMEP.S109037. [PubMed: 28144171]. [PubMed Central: PMC5245805].

30. Schwartzstein RM, Roberts DH. Saying goodbye to lectures in medical school - paradigm shift or passing fad? NEngl J Med. 2017;377(7):605-7. doi: 10.1056/NEJMp1706474. [PubMed: 28813217].

31. Jamal ABM. Workplace-based assessment: An important tool for trainee assessment. J Bangladesh Coll Physicians Surg. 2018;36(4):15965. doi: 10.3329/jbcps.v36i4.38185.

32. Maxwell J, Blashki G. Teaching about climate change in medical education: An opportunity. J Public Health Res. 2016;5(1):673. doi: 10.4081/jphr.2016.673. [PubMed: 27190980]. [PubMed Central: PMC4856872].

33. Salehmoghaddam AR, Mazloom SR, Sharafkhani M, Gholami H, Emami Zeydi A, Khorashadizadeh F, et al. Determinants of Social Accountability in Iranian Nursing and Midwifery Schools: A delphi study. Int J Community Based Nurs Midwifery. 2017;5(2):175-87. [PubMed: 28409171]. [PubMed Central: PMC5385240].

34. Yepes-Rios M, Dudek N, Duboyce R, Curtis J, Allard RJ, Varpio L. The failure to fail underperforming trainees in health professions education: A BEME systematic review: BEME guide no. 42. Med Teach. 2016;38(11):1092-9. doi: 10.1080/0142159X.2016.1215414. [PubMed: 27602533]. 